\title{
BMJ
}

\section{Alcohol attributable burden of incidence of cancer in eight European countries based on results from prospective cohort study}

\begin{abstract}
Madlen Schütze, PhD student, ${ }^{1}$ Heiner Boeing, professor, department chair, ${ }^{1}$ Tobias Pischon, scientist, group head, ${ }^{1}$ Jürgen Rehm, professor, director, ${ }^{2,3}$ Tara Kehoe, statistician, ${ }^{2}$ Gerrit Gmel, data analyst, ${ }^{2}$ Anja Olsen, scientist, ${ }^{4}$ Anne M Tjønneland, department head, ${ }^{4}$ Christina C Dahm, postdoctoral researcher, ${ }^{5}$ Kim Overvad, professor of epidemiology, ${ }^{6}$ Françoise Clavel-Chapelon, department head, ${ }^{7,8}$ Marie-Christine Boutron-Ruault, senior scientist, ${ }^{7,8}$ Antonia Trichopoulou, professor of nutrition, ${ }^{9}$ Vasiliki Benetou, scientist, ${ }^{10}$ Dimosthenis Zylis, scientist, ${ }^{10}$ Rudolf Kaaks, professor, division head, ${ }^{11}$ Sabine Rohrmann, senior scientist, ${ }^{11}$ Domenico Palli, unit chief, ${ }^{12}$ Franco Berrino, department chief, ${ }^{13}$ Rosario Tumino, director, ${ }^{14}$ Paolo Vineis, chair of environmental epidemiology, unit chief, ${ }^{15,28}$ Laudina Rodríguez, section chief, ${ }^{16}$ Antonio Agudo, scientist, ${ }^{17}$ María-José Sánchez, lecture director, ${ }^{18}$ Miren Dorronsoro, unit chief, ${ }^{19}$ Maria-Dolores Chirlaque, scientist, ${ }^{20,21}$ Aurelio Barricarte, department head, ${ }^{21}$ Petra H Peeters, professor of epidemiology, ${ }^{22}$ Carla H van Gils, associate professor of epidemiology, ${ }^{22}$ Kay-Tee Khaw, professor of clinical gerontology, ${ }^{23}$ Nick Wareham, director, ${ }^{24}$ Naomi E Allen, scientist, ${ }^{25}$ Timothy J Key, deputy director, ${ }^{25}$ Paolo Boffetta, professor, deputy director, ${ }^{26,27}$ Nadia Slimani, scientist, group head, ${ }^{26}$ Mazda Jenab, scientist, ${ }^{26}$ Dora Romaguera, research associate, ${ }^{28}$ Petra A Wark, research fellow, ${ }^{28}$ Elio Riboli, director, ${ }^{28}$ Manuela M Bergmann, scientist ${ }^{1}$
\end{abstract}

${ }^{1}$ Department of Epidemiology, German Institute of Human Nutrition Potsdam-Rehbruecke, 14558 Nuthetal, Germany

${ }^{2}$ Centre for Addiction and Mental Health (CAMH), Toronto, Canada

${ }^{3}$ Institute for Clinical Psychology and Psychotherapy, TU Dresden, Germany

${ }^{4}$ Institute of Cancer Epidemiology, Danish Cancer Society,

Copenhagen

${ }^{5}$ Department of Clinical Epidemiology, Aarhus University Hospital, Aalborg, Denmark

${ }^{6}$ Department of Epidemiology, School of Public Health, Aarhus University, Aarhus

${ }^{7}$ Centre for Research in Epidemiology and Population Health, U1018, Institut Gustave Roussy, F-94805, Villejuif, France

${ }^{8}$ Paris South University, UMRS 1018, F-94805, Villejuif

${ }^{9}$ WHO Collaborating Center for Food and Nutrition Policies, Department of Hygiene, Epidemiology and Medical Statistics, University of Athens Medical School and Hellenic Health Foundation, Greece

${ }^{10}$ WHO Collaborating Centre for Food and Nutrition Policies, Department of Hygiene, Epidemiology and Medical

\section{ABSTRACT}

Objective To compute the burden of cancer attributable to current and former alcohol consumption in eight European countries based on direct relative risk estimates from a cohort study.

Design Combination of prospective cohort study with representative population based data on alcohol exposure.

Setting Eight countries (France, Italy, Spain, United Kingdom, the Netherlands, Greece, Germany, Denmark) participating in the European Prospective Investigation into Cancer and Nutrition (EPIC) study.

Participants 109118 men and 254870 women, mainly aged 37-70.

Main outcome measures Hazard rate ratios expressing the relative risk of cancer incidence for former and current alcohol consumption among EPIC participants. Hazard rate ratios combined with representative information on alcohol consumption to calculate alcohol attributable fractions of causally related cancers by country and sex. Partial alcohol attributable fractions for consumption higher than the recommended upper limit (two drinks a day for men with about $24 \mathrm{~g}$ alcohol, one for women with about $12 \mathrm{~g}$ alcohol) and the estimated total annual number of cases of alcohol attributable cancer.

Results If we assume causality, among men and women, $10 \%$ (95\% confidence interval 7 to $13 \%$ ) and $3 \%$ (1 to $5 \%$ ) of the incidence of total cancer was attributable to former and current alcohol consumption in the selected European countries. For selected cancers the figures were
$44 \%$ (31 to $56 \%$ ) and $25 \%$ (5 to $46 \%$ ) for upper aerodigestive tract, $33 \%$ (11 to $54 \%$ ) and $18 \%$ ( -3 to $38 \%$ ) for liver, $17 \%$ (10 to $25 \%$ ) and $4 \%$ (-1 to $10 \%$ ) for colorectal cancer for men and women, respectively, and $5.0 \%$ ( 2 to $8 \%$ ) for female breast cancer. A substantial part of the alcohol attributable fraction in 2008 was associated with alcohol consumption higher than the recommended upper limit: 33037 of 178578 alcohol related cancer cases in men and 17470 of 397043 alcohol related cases in women.

Conclusions In western Europe, an important proportion of cases of cancer can be attributable to alcohol consumption, especially consumption higher than the recommended upper limits. These data support current political efforts to reduce or to abstain from alcohol consumption to reduce the incidence of cancer.

\section{INTRODUCTION}

Alcohol consumption is thought to account for a substantial number of deaths worldwide, with Europe and America showing the highest alcohol attributable fractions of $6.5 \%$ and $5.6 \%$, respectively. ${ }^{1}$ Chronic diseases, especially cancer, contribute markedly to this burden. In 2007 the International Agency for Research on Cancer (IARC) added two of the most common cancers - female breast and colorectal cancer-to the list of cancers causally related to alcohol, which previously consisted of oral cavity, pharynx, larynx, oesophagus, and liver cancer. ${ }^{2}$ Although alcohol consumption is a major risk factor for cancer incidence, ${ }^{3}$ 
Statistics, University of Athens Medical School

${ }^{11}$ Division of Cancer Epidemiology, German Cancer Research Centre, Heidelberg, Germany

${ }^{12}$ Molecular and Nutritional Epidemiology Unit, Cancer Research and Prevention Institute, Florence, Italy

${ }^{13}$ Department of Preventive and Predictive Medicine, Epidemiology Unit, Fondazione IRCCS Istituto Nazionale Tumori, Milan, Italy

${ }^{14}$ Cancer Registry and Histopathology Unit "Civile M.P. Arezzo" Hospital, ASP 7 Ragusa, Italy

${ }^{15}$ Institute for Scientific Interchange Foundation, Turin, Italy

${ }^{16}$ Public Health and Participation Directorate, Health and Health Care Services Council, Asturias, Spain

${ }^{17}$ Unit of Nutrition, Environment and Cancer, Cancer Epidemiology Research Programme, Catalan Institute of Oncology (IDIBELL), Barcelona, Spain

${ }^{18}$ Andalusian School of Public Health, Granada (Spain) and CIBER de Epidemiología y Salud Pública (CIBERESP), Spain

${ }^{19}$ Public Health Department of Gipuzkoa and CIBERESP, San Sebastian, Spain

${ }^{20}$ Department of Epidemiology, Murcia Regional Health Council, Murcia, Spain

${ }^{21}$ CIBER Epidemiología y Salud Pública (CIBERESP), Spain

${ }^{22}$ Centre for Health Sciences and Primary Care, University Medical Centre, Utrecht, Netherlands

${ }^{23}$ Department of Public Health and Primary Care, University of Cambridge, Cambridge, UK

${ }^{24}$ MRC Epidemiology Unit, Cambridge

${ }^{25}$ Cancer Epidemiology Unit, Nuffield Department of Clinical Medicine, University of Oxford, Oxford

${ }^{26}$ International Agency for Research on Cancer, IARC, Lyon, France

${ }^{27}$ Tisch Cancer Institute, Mount Sinai School of Medicine, New York, NY, USA

${ }^{28}$ Department of Epidemiology and Biostatistics, School of Public Health, Imperial College, London Correspondence to: M Schütze m.schuetze@dife.de

Cite this as: BMJ 2011;342:d1584 and Europe is among the regions with the highest per capita alcohol consumption, detailed information on the fractions of cancer that are attributable to alcohol consumption based on direct empirical evidence for the different cancer sites is sparse ${ }^{45}$ and systematic and comparable estimations across European countries are lacking. Moreover, previous estimates of the alcohol attributable fractions refer to the burden from current alcohol consumption but do not consider the risk of former alcohol consumption. Also, in 2007 the World Cancer Research Fund/American Institute for Cancer Research published recommendations on the maximum recommended daily alcohol consumption. ${ }^{6}$ We do not know how much of the burden of incidence of cancer is attributable to alcohol and occurs because of consumption higher than the recommended upper limit.

We estimated the total (current and former alcohol consumption) and partial (alcohol consumption higher than the recommended upper limit) alcohol attributable fractions for the incidence of total and specific cancers related to alcohol in eight European countries based on hazard rate ratios from the European Prospective Investigation into Cancer and Nutrition (EPIC) study and linked those alcohol attributable fractions to incidences of cancer to estimate the annual absolute number of cancer cases attributable to alcohol in these countries.

\section{METHODS}

\section{Study population}

The EPIC study is a multicentre prospective cohort study that, from 1992 to 2000, recruited about 520000 randomly selected men and women aged mainly 35-70 from 10 European countries. ${ }^{78}$ Eligible participants were selected from the general population, except in France, where selection was based on members of the health insurance system or state school employees, and in Utrecht (the Netherlands), where selection was based on women attending screening for breast cancer. Participants gave informed consent and completed questionnaires on diet and lifestyle. The present analyses included participants free from cancer at recruitment and who were not in the top or bottom $1 \%$ of the ratio of energy requirement to energy expenditure ( $\mathrm{n}=478478)$. Participants with incomplete information on alcohol consumption at recruitment or in the past $(\mathrm{n}=114481)$ and missing dietary information $(n=9)$ were excluded, leaving 363988 men and women from France, Italy, Spain, the Netherlands, United Kingdom, Greece, Germany, and Denmark. France and Utrecht enrolled only women. As we wanted to consider the risk of cancer incidence associated with former alcohol consumption, we had to exclude the centres of Norway, Sweden, Bilthoven, and Naples because they did not have information on past consumption.

Alcohol consumption at recruitment (in grams per day) was measured with a validated dietary questionnaire assessing frequency and portion size of beer/ cider, wine, spirits, and fortified wine covering the
12 months before recruitment. ${ }^{9-11}$ Consumption in the past was assessed as self reported consumption of beer, wine, and spirits at the ages of 20, 30, 40, and 50 . Based on consumption in the past and at recruitment we distinguished between never (no consumption in the past and no consumption at recruitment), former (consumption in the past but no consumption at recruitment), and lifetime consumers (consumption in the past and at recruitment). For lifetime consumers, consumption as applied in this analysis reflects the past years' consumption before recruitment.

We obtained information on incidence of cancer through record linkage with regional cancer registers in countries with passive follow-up (Denmark, Italy, the Netherlands, Spain, UK) or by a combination of methods including medically verified self reports of the participant or the next of kin, cancer or pathology registers, health insurance records, or death certificates in countries with active follow-up (France, Germany, Greece). The follow-up ended between 2002 and $2005,{ }^{12}$ and loss to follow-up was relatively low, with $<2 \%$ in all countries irrespective of active or passive follow-up. We investigated cancers with a causal association to alcohol consumption ${ }^{3}$ (colorectal (C18-21, ICD-O (international classification of diseases-oncology, 2nd revision), upper aerodigestive tract $(\mathrm{C} 00$ 10, C12-15, C32), liver (C22), female breast (C50)), as well as total cancer (C00-C80, except $\mathrm{C} 44$ skin cancer) and alcohol related cancers combined (upper aerodigestive tract, colorectal, liver, and, for women, female breast cancer). ICD codes of cancer end points were in accordance with the GLOBOCAN-2008 cancer definitions. ${ }^{13}$

\section{Statistical analysis}

We combined hazard rate ratios derived from the EPIC study with representative data on alcohol consumption from the general population. Cox proportional hazard regressions were applied to compute hazard rate ratios ${ }^{14}$ during a mean follow-up time of 8 . 8 years for alcohol consumption among lifetime consumers per $12 \mathrm{~g} /$ day increment (equivalent to one drink of any alcoholic beverage) and for former compared with never consumers and incidence of first primary cancer. Age was used as the underlying time variable with entry and exit time defined as the participant's age at recruitment and age at diagnosis of cancer or at censoring, respectively. Results on some single cancer outcomes have been published earlier. ${ }^{15-20} \mathrm{We}$ used updated information and recomputed hazard rate ratios for these sites. To control for age and variations in study procedures across the EPIC centres we stratified the analyses by age (in 1 year categories) and centre.

All models were run separately for men and women, and included the following potential confounders, which were measured at recruitment: smoking (never; past $<10$ years ago, $\geq 10$ years ago; current $<15,15-25$, or $\geq 25$ cigarettes/day, other (cigars, pipe, cigarettes with missing dose)) and smoking duration $(<10,10-<20,20-<30,30-<40, \geq 40$ years, missing 
(4.1\%)); education (higher education/university, technical school, secondary school, primary school, none or missing $(1.2 \%))$; physical activity (inactive, moderately inactive, moderately active, active ${ }^{21}$; body mass index $\left(\mathrm{BMI} ; \mathrm{kg} / \mathrm{m}^{2}\right)$; consumption (g/day) of meat and meat products, fish, fruits and vegetables; fibre, and non-alcohol energy intake (kJ/day); and, for women, menopausal status (premenopausal, postmenopausal/ surgical, perimenopausal), age at menarche $(<13,13 /$ $14,>14$ years, missing $(30.8 \%))$, and whether she had ever breast fed (yes, no, or missing (32.9\%)), ever used oral contraceptives (yes, no, or missing $(31.6 \%))$, and ever used hormone replacement therapy (yes, no, or missing $(30.6 \%))$.

Restricted cubic spline regressions (knots: p10, p50, p90 and p25, p50, p75) did not indicate deviation from linearity of associations between alcohol and risk of cancer among lifetime consumers, except for liver cancer in men $(\mathrm{P}<0.01$ for non-linearity). We therefore used regression coefficients $(\beta)$ as risk functions to express the risk for cancer incidence per $1 \mathrm{~g}$ /day increment in alcohol consumption among current lifetime consumers. For simplicity and for comparability we also used this approach for liver cancer in men.

We tested effect modification by smoking for the site specific cancers by including product terms of smoking status (never, former, current smoker) with alcohol (g/ day) and performing the likelihood ratio test between nested models. There was indication for an effect modification by smoking for upper aerodigestive tract and liver cancer in men and for colorectal cancer in women $(\mathrm{P}<0.1)$.

Heterogeneity of hazard rate ratios across centres was examined by the meta-analytic approach ${ }^{22} 23$ and by including interaction terms of centre and alcohol (g/day) in the models and applying likelihood ratio tests between nested models. There was significant heterogeneity across centres for liver cancer in men and colorectal cancer in women. Reasons for heterogeneity are unknown. Reduction in alcohol consumption could have been the consequence of pre-diagnostic diseases (such as liver cirrhosis) or positive results on screening (such as for liver function markers or colon polyps) performed in some but not all EPIC countries. This could lead to reverse causation ${ }^{2425}$ and thus to attenuation of the association between alcohol and cancer in these centres, resulting in heterogeneity of the association across centres. This speculation was supported by the fact that the heterogeneity was no longer present when we excluded the first four years of follow-up.

All statistical tests were two sided with significance at the $5 \%$ level.

\section{Alcohol attributable fractions}

The computation of alcohol attributable fractions requires not only the information on relative risks for alcohol consumption (such as hazard rate ratios) but also information on the distribution of alcohol consumption within the general population. We computed alcohol exposure data from the general population following an algorithm (triangulation) ${ }^{26}$ that combined information of alcohol consumption from survey data as reported by the World Health Organization ${ }^{27}$ and per capita consumption ${ }^{28}$ for each country and separately for men and women aged $\geq 15$. These sex and country specific data on alcohol exposure were modelled as gamma function ${ }^{29}$ in current consumers of alcohol by applying a formula ${ }^{30}$ based on the triangulated population mean alcohol intake (combining alcohol survey information with data on per capita alcohol consumption). ${ }^{26}$ These gamma functions were shown to fit and best model the right skewed distribution of alcohol consumption on the population level. Furthermore, this exhibits the clear advantage of using alcohol consumption continuously, as the estimation of alcohol attributable fractions based on alcohol categories might lose valuable information. We also obtained information on the proportions of never and former consumers of alcohol from WHO, which used the GENACIS survey as source of information, except for Greece, for which data were derived from a national survey on licit and illicit drug use. ${ }^{31}$ We then calculated the country and sex specific alcohol attributable fractions reflecting the burden of cancer incidence associated with total alcohol consumption on the population level (equation A, fig 1).

We also computed the part of the alcohol attributable fraction (partial alcohol attributable fraction) that reflects the burden of cancer incidence associated with alcohol consumption higher than the recommended upper limit ${ }^{6}$ of two standard drinks a day $(>24 \mathrm{~g} /$ day) for men and one standard drink a day (>12 g/day) in women (equation B, fig 1).

For adjusted risk estimates, the prevalence of exposure among cases rather than among the general popu-

$$
\begin{aligned}
& \text { Equation A } \\
& \qquad A F=\frac{P_{N C} \cdot 1+P_{F C} \cdot H R R_{F C}+\int_{0.0001 \mathrm{~g} / \text { day }}^{250 \mathrm{~g} / \text { day }} P_{L C}(x) \cdot H R R(x) d x-1}{P_{N C} \cdot 1+P_{F C} \cdot H R R_{F C}+\int_{0.0001}^{250 \mathrm{~g} / \text { day } / \text { day }} P_{L C}(x) \cdot H R R(x) d x}
\end{aligned}
$$

where $P_{N C}, P_{F C}$, and $P_{L C}=$ prevalence of never (\%), former (\%), or lifetime consumers (\% and gamma distribution), respectively $\operatorname{HRR}(x)=$ risk of cancer per consumed gram of alcohol a day for lifetime consumers

$H R R_{F C}=$ risk of cancer incidence in former compared with never consumers

$$
A A F_{\text {Men } 24 \mathrm{~g} / \text { day }}=\frac{\int_{24 \mathrm{~g} / \text { day }}^{250 \mathrm{~g} / \text { day }} P_{L C}(x) \cdot H R R(x) d x-P_{L C>24 \mathrm{~g} / \text { day }}}{P_{N C} \cdot 1+P_{F C} \cdot H R R_{F C}+\int_{0.0001 \mathrm{~g} / \text { day }}^{250 \mathrm{~g} / \mathrm{day}} P_{L C}(x) \cdot H R R(x) d x}
$$

where $P_{L C) 24 \mathrm{~g} / \text { day }}=$ proportion of lifetime consumers with consumption larger than recommended upper limit Counterfactual scenario for total and partial alcohol attributable fraction was complete elimination of alcohol consumption in population

Fig 1| Equations for computation of alcohol attributable fractions 
Table 1|Proportions of never, former, and lifetime consumers of alcohol and mean alcohol consumption in lifetime consumers in general adult population aged 15 years or older

\begin{tabular}{|c|c|c|c|c|c|}
\hline Country & $\begin{array}{c}\text { Never } \\
\text { consumers (\%) }\end{array}$ & $\begin{array}{c}\text { Former } \\
\text { consumers (\%) }\end{array}$ & $\begin{array}{c}\text { Lifetime } \\
\text { consumers (\%) }\end{array}$ & $\begin{array}{c}\text { Mean* } \\
\text { (SD) g/day }\end{array}$ & $\begin{array}{l}\% \text { drinking over } \\
\text { daily recommended } \\
\text { upper limit } \dagger\end{array}$ \\
\hline \multicolumn{6}{|l|}{ Men } \\
\hline Denmark & 0.6 & 2.5 & 96.9 & $32.9(38.7)$ & 42.6 \\
\hline Germany & 1.3 & 2.6 & 96.1 & $34.9(41.0)$ & 43.8 \\
\hline Greece & 6.7 & 9.3 & 84.0 & $27.4(32.3)$ & 32.4 \\
\hline Italy & 5.8 & 3.9 & 90.3 & $30.1(35.3)$ & 37.3 \\
\hline Spain & 9.5 & 23.4 & 67.1 & $33.0(38.8)$ & 29.5 \\
\hline UK & 8.9 & 1.5 & 89.7 & $35.2(41.4)$ & 41.1 \\
\hline Total & 5.6 & 6.2 & 88.2 & $33.2(39.0)$ & 39.0 \\
\hline \multicolumn{6}{|l|}{ Women } \\
\hline Denmark & 0.9 & 7.0 & 92.1 & $17.5(21.5)$ & 41.0 \\
\hline France & 3.3 & 7.1 & 89.6 & $16.7(20.6)$ & 38.7 \\
\hline Germany & 2.0 & 2.6 & 95.3 & $18.1(22.3)$ & 43.5 \\
\hline Greece & 21.0 & 19.0 & 60.0 & $14.4(17.9)$ & 23.4 \\
\hline Italy & 19.4 & 6.0 & 74.6 & $12.4(15.6)$ & 25.8 \\
\hline Netherlands & 16.7 & 19.1 & 64.1 & $15.4(18.1)$ & 27.1 \\
\hline Spain & 24.7 & 31.6 & 43.8 & $13.4(16.7)$ & 16.1 \\
\hline UK & 15.2 & 2.9 & 81.9 & $17.6(20.6)$ & 37.7 \\
\hline Total & 11.7 & 9.0 & 79.3 & $15.9(19.7)$ & 33.2 \\
\hline
\end{tabular}

*Mean alcohol consumption computed among lifetime consumers.

$\dagger>24 \mathrm{~g} /$ day in men; $>12 \mathrm{~g} /$ day in women.

fWeighted average by using population size data of population from each country.

lation should be used, ${ }^{32-36}$ which is hardly feasible because no exposure information in cases from the general population is available. We therefore performed sensitivity analyses by simulating the distribution of alcohol exposure among cases by using the alcohol exposure information in cancer cases in the EPIC study and shifting this curve towards the alcohol exposure information of the general population (by deriving weights by dividing the gamma distribution of the general population by the gamma distribution of the EPIC participants). Doing so, we simulated the alcohol exposure distribution of cases as if they originated from the general population. As expected, the estimated mean alcohol consumption among cancer cases was higher than among the general population. Alcohol attributable fractions were stratified by sex but not by country because of sparse numbers of cases in some countries. This was also why we applied this approach as a sensitivity analysis and not as our main approach.

As smoking seemed to modify the association between alcohol and cancers of the upper aerodigestive tract and liver in men and colorectal cancer in women, we also computed hazard rate ratios for alcohol intake (continuous, per $12 \mathrm{~g}$ /day and for former $v$ never consumers) and cancer incidence among never smokers. For upper aerodigestive tract and liver cancer the number of cases became low in men. We therefore computed the hazard rate ratios in never smokers for men and women combined with additional adjustment for sex. Alcohol attributable fractions were recomputed by replacing the smoking adjusted hazard rate ratios from the total EPIC cohort by the hazard rate ratios in never smokers.
We used 10000 Monte-Carlo simulated alcohol attributable fractions, considering the uncertainty of the hazard rate ratios, to compute the variances, standard errors, and corresponding 95\% confidence intervals of the alcohol attributable fractions. We estimated the absolute number of alcohol attributable cancer cases by multiplying the alcohol attributable fractions with the total number of incidental cancer cases from 2008 derived from the GLOBOCAN 2008 project. $^{13}$

The analyses were performed with SAS, version 9.2, and $\mathrm{R}$, version 2.9.1.

\section{RESULTS}

Across the countries investigated, alcohol consumption followed a north south gradient with Greece and Spain having the highest proportions of never and former consumers, and Denmark and Germany having the highest proportion of lifetime consumers (table 1). This gradient was also seen for the proportions of alcohol consumption higher than the recommended upper limit with Greece and Spain showing the lowest and Germany and Denmark the highest proportions.

Among male and female lifetime consumers, the risk for all the cancers we included increased with each additional drink a day (table 2). Former consumption compared with never was associated with a considerably higher risk for total and alcohol related cancer in men. We could not compute the risk for former consumers of alcohol and upper aerodigestive tract and liver cancer in men because of low number of cases in those who had never consumed alcohol. Hence, we
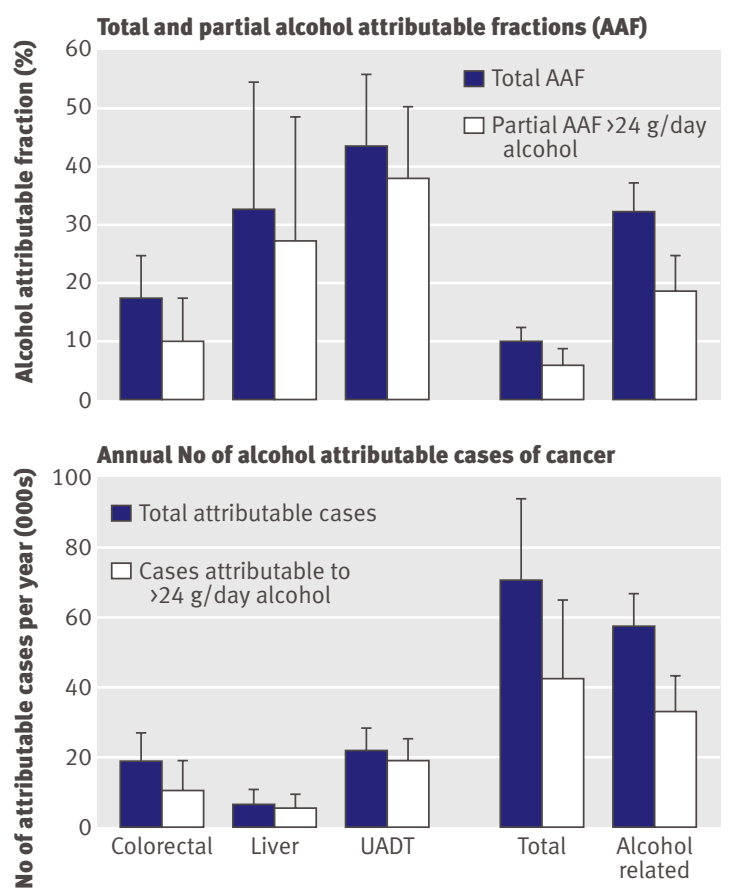

Cancer

Fig 2 | Total and partial alcohol attributable fractions with $95 \%$ confidence intervals and corresponding number of cases of cancer with $95 \%$ confidence intervals in men in selected EPIC countries (Italy, Spain, UK, Greece, Germany, Denmark) in 2008. UADT=upper aerodigestive tract 
Table 2 Adjusted hazard rate ratios (HRRs)* $(95 \%$ confidence intervals) per $12 \mathrm{~g} /$ day increment for lifetime consumers and for former versus never consumers (reference category) of alcohol

\begin{tabular}{|c|c|c|c|c|}
\hline \multirow[b]{2}{*}{ Cancer site } & \multicolumn{2}{|c|}{ Continuous (per $12 \mathrm{~g} /$ day) $\dagger$} & \multicolumn{2}{|c|}{ Former consumers $\ddagger$} \\
\hline & No of cases & $\operatorname{HRR}(95 \% \mathrm{Cl})$ & No of cases & HRR $(95 \% \mathrm{Cl})$ \\
\hline \multicolumn{5}{|l|}{ Men } \\
\hline Total cancer & 5726 & $1.03(1.02$ to 1.04$)$ & 403 & 1.54 (1.20 to 1.98$)$ \\
\hline Alcohol related & 1235 & 1.10 (1.07 to 1.12$)$ & 91 & $3.72(1.81$ to 7.65$)$ \\
\hline Upper aerodigestive tract & 272 & $1.17(1.12$ to 1.23$)$ & - & $1.54 \S(1.20$ to 1.98$)$ \\
\hline Colorectum & 859 & 1.05 (1.02 to 1.09$)$ & 53 & 2.19 (0.99 to 4.83$)$ \\
\hline Liver & 104 & 1.13 (1.04 to 1.22$)$ & - & $1.54 \S(1.20$ to 1.98$)$ \\
\hline \multicolumn{5}{|l|}{ Women } \\
\hline Total cancer & 12467 & $1.03(1.01$ to 1.05$)$ & 776 & 1.10 (1.01 to 1.20$)$ \\
\hline Alcohol related & 6671 & 1.05 (1.03 to 1.07$)$ & 354 & 1.04 (0.92 to 1.19$)$ \\
\hline Upper aerodigestive tract & 113 & 1.25 (1.10 to 1.42$)$ & 9 & 0.65 (0.27 to 1.56$)$ \\
\hline Colorectum & 1245 & 1.04 (0.99 to 1.09$)$ & 79 & 1.05 (0.79 to 1.40$)$ \\
\hline Liver & 54 & 1.09 (0.89 to 1.33$)$ & 10 & 2.28 (0.89 to 5.85$)$ \\
\hline Breast & 5259 & 1.05 (1.02 to 1.07$)$ & 256 & $1.03(0.88$ to 1.20$)$ \\
\hline
\end{tabular}

*Adjusted for smoking (dose and duration); education; physical activity; BMI; consumption of meat, fish, fruit and vegetables; fibre, and non-alcoholic energy intake (kJ/day); and, for women additionally, menopausal status, age at menarche, breast feeding, oral contraceptive use, hormone replacement therapy.

†Among lifetime consumers (102 648 men, 216149 women). Log linear estimates used to establish risk functions.

$\ddagger$ Reference category=never consumers of alcohol.

$\S W h e n$ there were no or a limited number of cases in reference category of never consumers, HRR for total cancer was used. because of the lower proportions of men consuming more than two drinks a day. In women, partial alcohol attributable fractions accounted for $3 \%$ of colorectal cancer, $4 \%$ of breast cancer, $7 \%$ of liver cancer, and $25 \%$ of upper aerodigestive tract cancer (fig 3), which accounted for $40 \%$ to $98 \%$ of the total alcohol attributable fractions. For all cancers investigated in women, the partial alcohol attributable fraction was lowest in Spain, Greece, and Italy and highest in Germany, Denmark, and the UK. When we compared total with partial alcohol attributable fractions, a substantial part (40$98 \%$ ) of the incidence of alcohol attributable cancer occurred because of alcohol consumption higher than the recommended upper limit in both men and women. The remaining part of the total alcohol attributable fraction (2-60\%) was associated with consumption of less than the recommended upper limit and former consumption. In men, about three in 100 alcohol related cancer cases were associated with alcohol consumption of $\leq 24 \mathrm{~g} /$ day and more than 18 in 100 were associated with alcohol consumption $>24 \mathrm{~g} /$ day. In women one in 100 alcohol attributable cancer cases was associated with alcohol consumption of $\leq 12 \mathrm{~g} /$ day and about four in 100 associated with alcohol consumption $>12 \mathrm{~g} /$ day.

In terms of total numbers of cases of alcohol related cancer, and if we accept that there is a causal association between alcohol consumption and occurrence of cancer, in 2008, 33037 of 178578 alcohol related cancer cases in men and 17470 of 397043 alcohol related cancer cases in women were associated with alcohol
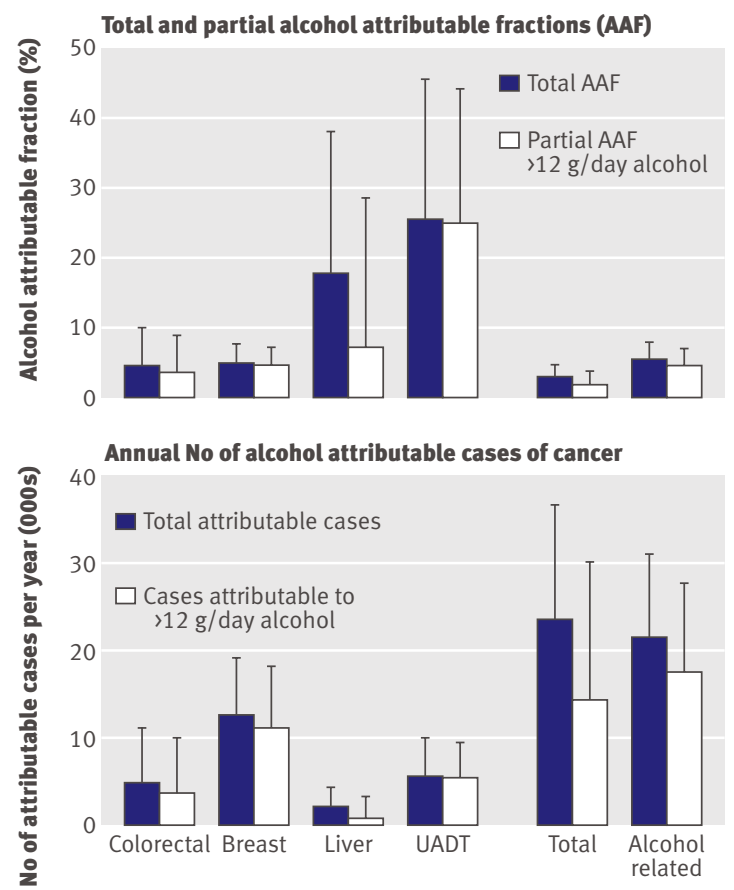

Cancer

Fig 3 | Total and partial alcohol attributable fractions with $95 \%$ confidence intervals and corresponding number of cases of cancer with $95 \%$ confidence intervals in women in selected EPIC countries (France, Italy, Spain, UK, Netherlands, Greece, Germany, Denmark) in 2008. UADT=upper aerodigestive tract 
Table 3|Proportion of cancer cases attributable to alcohol use in men aged $\geq 15$ years. Figures are percentages $(95 \%$ confidence interval)

\begin{tabular}{|c|c|c|c|c|c|c|c|}
\hline Cancer site & Denmark & Germany & Greece & Italy & Spain & UK & Total \\
\hline Total cancer & 8 (5 to 12$)$ & $9(5$ to 12$)$ & 10 (7 to 12$)$ & $8(5$ to 11$)$ & 15 (13 to 17$)$ & $8(5$ to 11$)$ & 10 (7 to 13$)$ \\
\hline Alcohol related & 29 (22 to 35$)$ & 30 (23 to 37$)$ & 33 (29 to 36$)$ & 28 (23 to 33$)$ & $46(44$ to 49$)$ & 27 (21 to 34$)$ & 32 (27 to 38$)$ \\
\hline Upper aerodigestive tract & 45 (32 to 57$)$ & 47 (34 to 60$)$ & 37 (26 to 47$)$ & 40 (29 to 52$)$ & 41 (31 to 51$)$ & 45 (32 to 58$)$ & 44 (31 to 56$)$ \\
\hline Colorectum & 15 (7 to 24$)$ & $16(7$ to 25$)$ & 18 (12 to 23$)$ & 15 (8 to 22$)$ & 28 (23 to 32$)$ & 14 (5 to 23$)$ & 17 (10 to 25$)$ \\
\hline Liver & 34 (10 to 57$)$ & 35 (11 to 59$)$ & 28 (10 to 45$)$ & $30(9$ to 51$)$ & 32 (15 to 49$)$ & 33 (10 to 57$)$ & 33 (11 to 54$)$ \\
\hline
\end{tabular}

consumption of more than two (one for women) drinks a day. Cancer of the upper aerodigestive tract accounted for the highest number of alcohol attributable cases in men (22 022 cases), with Germany showing most cases (table 5). In women, breast cancer contributed most to the number of alcohol attributable cancer cases with 12589 cases (fig 2, table 5). The numbers of total alcohol attributable cancer cases varied considerably by country, mainly because of different population sizes in the investigated countries but also because of varying alcohol attributable fractions across the countries.

The sensitivity analysis using the alcohol consumption data in the cancer cases only had similar results to those in tables 3 and 4 (data not shown). The maximum deviation was 3 percentage points in men for alcohol related cancers $(29 \% v 32 \%)$ and 2 percentage points in women for upper aerodigestive tract cancer $(23 \%$ v 25\%).

Given there is a causal association between alcohol consumption and risk of cancer in people who have never smoked, sensitivity analyses with the hazard rate ratios of never smokers indicated noticeable differences compared with alcohol attributable fractions that were based on hazard rate ratios adjusted for smoking from the total cohort, particularly for liver cancer, for which the alcohol attributable fraction in men who had never smoked $\left(\mathrm{AAF}_{\text {Sens }}\right)$ was $78 \%$ compared with $33 \%$ in the total population, and for upper aerodigestive tract cancer, for which the $\mathrm{AAF}_{\text {Sens }}$ was $14 \%$ compared with $44 \%$. The alcohol attributable fractions for colorectal cancer in women differed by 3 percentage points with $\mathrm{AAF}_{\text {Sens }} 1 \% v 4 \%$, which was, however, within the confidence interval computed for the alcohol attributable fraction based on estimates of the total cohort.

\section{DISCUSSION}

If we assume causality, our analysis shows that about $10 \%$ of total cancer in men and 3\% in women could be attributed to current and former alcohol consumption in the European countries included in this study. In relative terms, the alcohol attributable fraction of cancer incidence was highest for cancer of the upper aerodigestive tract, followed by liver cancer. The highest absolute number of alcohol attributable cancer cases in men was found for upper aerodigestive tract and in women for breast cancer. Furthermore, a substantial part of the alcohol attributable cancer cases were associated with consumption of more than two or one standard drinks per day for men and women, respectively.

\section{Comparison with other studies}

Few previous studies have reported on alcohol attributable mortality ${ }^{37-43}$ or incidence ${ }^{45445}$ of cancer. Published estimates for alcohol attributable incidence of cancer in Europe ${ }^{38}$ and France ${ }^{44}$ were of similar magnitude to our estimates. For women both higher ${ }^{545}$ and lower $^{44}$ alcohol attributable fractions for single cancer sites were reported. Differences could emerge because we considered also the risk of cancer associated with former consumption of alcohol, or because of the risk functions used by one study, ${ }^{44}$ which were not derived for men and women separately, ${ }^{46}$ or because of the different application of alcohol exposure data. One British study used population means of alcohol consumption, ${ }^{5}$ while we applied gamma distributions, which better represent the right skewness of the data on alcohol consumption. Because of the various methods used to compute the alcohol attributable fractions in previous studies and because of limited data, no comparable estimates across the European countries on the alcohol attributable burden of cancer have been available until now.

Besides the total burden, we also quantified the burden of cancer incidence associated with exceeding the recommended maximal daily limit of alcohol. We found that a substantial part of this incidence was associated with consumption above the recommended upper limit, indicating the potential for cancer prevention merely by adhering to the current recommendations. For cancer sites with markedly higher risks for former compared with never consumers - such as liver cancer - a noticeable part of the total alcohol attributable fractions was associated with former consumption. That also explains why for those cancers the partial alcohol attributable fractions associated with consumption above the recommended upper limit were lower than for cancers with less strong risk estimates in former consumers, such as breast cancer. Alcohol consumption below the recommended upper limit accounted for a modest part of the total alcohol attributable fraction of alcohol related cancers, with at least three in 100 cases of cancer in men and one in 100 cases in women. This shows that following the current recommendation would not eliminate alcohol attributable cancer incidence completely. In contrast, for all cause mortality alcohol consumption is often shown to be associated with a lower risk for up to four drinks a day in men and two drinks a day in women. ${ }^{47}$ This lower risk is probably because of the lower risk of death from cardiovascular disease, 
Table 4 |Proportion of cancer cases attributable to alcohol use in women aged $\geq 15$ years. Figures are percentages ( $95 \%$ confidence interval)

\begin{tabular}{|c|c|c|c|c|c|c|c|c|c|}
\hline Cancer site & Denmark & France & Germany & Greece & Italy & Netherlands & Spain & UK & Total \\
\hline Total cancer & 3 (1 to 5$)$ & 3 (1 to 5$)$ & 3 (1 to 5$)$ & $3(2$ to 4$)$ & 2 (1 to 3$)$ & $3(2$ to 5$)$ & 4 (3 to 5$)$ & 3 (1 to 5$)$ & 3 (1 to 5$)$ \\
\hline Alcohol related & 7 (4 to 10$)$ & 6 (4 to 9$)$ & 7 (4 to 10$)$ & $4(3$ to 6$)$ & $4(2$ to 6$)$ & 5 (3 to 7$)$ & $4(3$ to 5$)$ & 6 (3 to 9) & 5 (3 to 8$)$ \\
\hline Upper aerodigestive tract & 32 (9 to 55$)$ & 30 (8 to 52$)$ & 35 (11 to 59$)$ & $15(-1$ to 31$)$ & $18(4$ to 32$)$ & 17 (0 to 34) & $5(-8$ to 18$)$ & $30(9$ to 51$)$ & $25(5$ to 46$)$ \\
\hline Colorectum & $5(-2$ to 12$)$ & $5(-1$ to 11$)$ & $6(-2$ to 13$)$ & $4(0$ to 7$)$ & $3(-1$ to 7$)$ & $4(0$ to 8$)$ & $3(1$ to 6$)$ & $5(-2$ to 11$)$ & $4(-1$ to 10$)$ \\
\hline Liver & $18(-8$ to 44$)$ & $17(-7$ to 42$)$ & 15 (-16 to 46$)$ & 24 (12 to 36$)$ & $13(-3$ to 29$)$ & 24 (11 to 38$)$ & 31 (24 to 38$)$ & $13(-13$ to 39$)$ & $18(-3$ to 38$)$ \\
\hline Breast & $6(3$ to 10$)$ & 6 (3 to 9) & 7 (3 to 10$)$ & $4(2$ to 6$)$ & $4(2$ to 6$)$ & $4(2$ to 6$)$ & $3(2$ to 4$)$ & $5(2$ to 8$)$ & $5(2$ to 8$)$ \\
\hline
\end{tabular}

especially coronary heart disease and ischaemic stroke. $^{48-50}$ Heavy alcohol consumption above the recommended upper limit, however, was shown to be not related to ${ }^{48}$ or detrimental for ${ }^{46}$ cardiovascular diseases, whereas for cancer, as shown by many studies $^{4651}$ including ours, there is no sensible limit below which the risk of cancer is decreased. Therefore, even though light to moderate alcohol consumption might decrease the risk for cardiovascular disease and mortality, the net effect of alcohol is harmful. ${ }^{1}$ Thus, alcohol consumption should not be recommended to prevent cardiovascular disease or all cause mortality.

\section{Sensitivity analysis}

Smoking, known to be closely related to alcohol consumption, could be a potential synergistic risk factor, particularly for cancer of the upper aerodigestive tract. A possible synergistic effect modification of smoking on the risk of alcohol and cancer could lead to an overestimation of the alcohol attributable fraction. ${ }^{52} \mathrm{We}$ observed a substantially higher alcohol attributable fraction for liver cancer and a considerably lower alcohol attributable fraction for upper aerodigestive tract cancer in men when we applied the hazard rate ratios for alcohol consumption among never smokers. Potential effect modification by smoking was also indicated for colorectal cancer in women, for which the alcohol attributable fraction computed by using hazard rate ratios among never smokers was lower than the overall alcohol attributable fraction, but within the $95 \%$ confidence interval. In the groups of never smokers the number of cases of cancer was limited in the EPIC study, which led to a limited power to assess the association between the consumption of alcohol and risk of cancer in this subgroup. This could be one explanation why the alcohol attributable fractions differed from the originally computed overall alcohol attributable fractions. We could also have overestimated the alcohol attributable fraction for upper aerodigestive tract cancer in men because of the effect of smoking. However, a recent pooled analysis of 17 European and American case-control studies investigating people who had ever consumed alcohol compared with those who had never consumed alcohol in relation to head and neck cancer in people who had never smoked, ${ }^{453}$ estimated a population attributable fraction of $29.5 \%$ in men and $31.5 \%$ women. These estimates are of similar magnitude to our estimates based on results from the total EPIC study population, suggesting the estimates of our overall alcohol attributable fractions to be valid. Regarding liver cancer, smoking is a recognised causal risk factor. ${ }^{3}$ Thus, there is no plausible explanation for the substantial higher alcohol attributable fraction for liver cancer based on risk estimates computed in those who had never smoked. Therefore, the limited power because of low numbers of cases and the resulting imprecise point estimates of the hazard rate ratios in never smokers is the most plausible explanation for the considerably higher alcohol attributable fraction of liver cancer.

Table 5 | Total number* of alcohol attributable cancer cases for general population in 2008 in selected countries

\begin{tabular}{|c|c|c|c|c|c|c|c|c|c|}
\hline Cancer site & Denmark & France & Germany & Greece & Italy & Netherlands & Spain & UK & Total \\
\hline \multicolumn{10}{|l|}{ Men } \\
\hline Total & 1313 & NA & 22388 & 1968 & 14556 & NA & 18173 & 12564 & 71519 \\
\hline Alcohol related & 996 & NA & 17967 & 1107 & 12332 & NA & 14295 & 9299 & 57596 \\
\hline Upper aerodigestive tract & 445 & NA & 7864 & 351 & 7045 & NA & 4236 & 5133 & 22022 \\
\hline Colorectum & 348 & NA & 6053 & 318 & 4206 & NA & 4602 & 2936 & 18836 \\
\hline Liver & 64 & NA & 1797 & 178 & 2414 & NA & 1170 & 700 & 6465 \\
\hline \multicolumn{10}{|l|}{ Women } \\
\hline Total & 503 & 4415 & 6561 & 524 & 3254 & 1282 & 2996 & 3791 & 23307 \\
\hline Alcohol related & 459 & 4717 & 7240 & 293 & 2076 & 939 & 1376 & 4058 & 21520 \\
\hline Upper aerodigestive tract & 146 & 1359 & 1698 & 39 & 528 & 217 & 395 & 1589 & 5499 \\
\hline Colorectal & 116 & 923 & 1771 & 59 & 744 & 221 & 411 & 787 & 4919 \\
\hline Liver & 13 & 269 & 376 & 78 & 529 & 29 & 442 & 169 & 2020 \\
\hline Breast & 259 & 2956 & 4193 & 177 & 1734 & 550 & 680 & 2498 & 12589 \\
\hline
\end{tabular}

NA=not applicable.

*Numbers refer to total burden of incident cancer cases associated with current and former alcohol consumption in population. Sum of cases for single countries might not exactly add to total number of cases because of country specific estimation of numbers and separate estimation for all countries combined. 


\section{WHAT IS ALREADY KNOWN ON THIS TOPIC}

Alcohol consumption has been causally related to cancers of the oral cavity, pharynx, larynx, oesophagus, liver, colorectum, and female breast

Current estimates of the alcohol attributable burden of these cancers refer mostly to current alcohol consumption and to Europe as a whole, and do not include the risk associated with previous alcohol consumption

\section{WHAT THIS STUDY ADDS}

If we assume causality between alcohol consumption and cancer, about $10 \%$ of all cancer cases in men and $3 \%$ of all cancer cases in women are attributable to current and former alcohol consumption in the investigated European countries

For cancers that are causally related to alcohol consumption, the proportions were $32 \%$ in men and $5 \%$ in women, with a substantial part (40-98\%) being attributable to current alcohol consumption above the recommended upper limit of two drinks a day in men and one drink a day in women the European countries, however, we would also expect the burden of alcohol attributable cancer incidence to differ across the countries, which is of potential interest for public health policy makers.

We have provided a systematic and comparable overview of the alcohol attributable cancer incidence for several European countries, and presented alcohol attributable fractions for causally related cancer sites based on empirical original data for both the total (current and former) alcohol consumption as well as for alcohol consumption higher than the recommended upper limit. We considered the risk from former alcohol consumption and could thus capture, in contrast with previous studies, the full burden of cancer incidence associated with alcohol consumption. The gamma distributions we used for current alcohol consumption overcome the limitation of using categorical risk estimates and categories of proportions of alcohol consumption. This is of particular value because the risk of cancer increases linearly and alcohol consumption follows a strongly right skewed distribution. The attributable burden of cancer incidence associated with consuming above the recommended upper limit illustrates the potential of avoidable cancer incidence, if the recommendations of the WCRF/AICR ${ }^{6}$ are followed. Until now, it was only speculated that reducing alcohol consumption to two drinks a day in men and one drink a day in women would be beneficial in terms of incidence of cancer. We have now computed quantitative measures, both relative (alcohol attributable fraction) and absolute (total number of cancer cases), for the burden associated with alcohol consumption above the recommended upper limit.

\section{Conclusions and policy implications}

In conclusion, if we assume causality between alcohol consumption and overall and specific cancer incidence, a considerable proportion of the most common and most lethal cancers is attributable to former and current alcohol consumption in the selected European countries, especially to consumption above the recommended upper limit. This strongly underlines the necessity to continue and to increase efforts to reduce alcohol consumption in Europe,${ }^{56}$ both on the individual and the population level.

Contributors: All authors had full access to all of the data (including statistical reports and tables) and take responsibility for the integrity of the data and the accuracy of the data analysis. All authors MS, MMB, TP $H B, J R, T K$, and ER were responsible for study concept and design. $H B$, TJK, K-TK, PP, AB, MD, M-DC, MJS, LR, AA, PV, RT, FB, DP, AT, RK, FC-C, KO AMT, AO, CD, M-CB-R, VB, DZ, SR, CVG, NW, MJ, NS, DR, PAW, and ER acquired the data. MS, MMB, HB, TP, JR, TK, GG, PB, NEA, and PP analysed and interpreted the data. MS, MB, TP, HB, JR, TK, NEA, KO, PP, and PB drafted the manuscript, which was critically revised for important intellectual content by all the authors. MS, JR, TK, GG, TP, and MMB were responsible for the statistical analysis. MMB, JR, and $H B$ supervised the study. MS is guarantor

Funding: The work was performed (partly) within the coordinated action EPIC (SP23-CT-2005-006438), which has received research funding from the Community's Sixth Framework Programme, as well as by the "Europe Against Cancer" Programme of the European Commission (SANCO); Deutsche Krebshilfe; German Cancer Research Center; German Federal Ministry of Education and Research; Danish Cancer Society; Health Research Fund (FIS) of the Spanish Ministry of Health (grant No: 
Network RCESP C03/09); Spanish Regional Governments of Andalucia, Asturias, Basque Country, Murcia and Navarra; ISCIII, Red de Centros RETIC(RD06/0020) (grant No: C03/09); Cancer Research UK; Medical Research Council, UK; Stroke Association, UK; British Heart Foundation; Department of Health, UK; Food Standards Agency, UK; Wellcome Trust, UK; Italian Association for Research on Cancer (AIRC); Compagnia di San Paolo; Progetto Integrato Oncologia-PIO, Regione Toscana; Dutch Ministry of Public Health, Welfare and Sports; National Cancer Registry of the Netherlands; Greek Ministry of Health and Social Solidarity; Hellenic Health Foundation and Stavros Niarchos Foundation. The funders were independent of the research of the presented study.

Role of sponsors: The sponsors had no input in the design, the conduct, the analysis, or the interpretation of the study, and did not influence the manuscript preparation.

Competing interests: All authors have completed the Unified Competing Interest form at www.icmje.org/coi_disclosure.pdf (available on request from the corresponding author) and declare: no support from any organisation for the submitted work; no financial relationships with any organisations that might have an interest in the submitted work in the previous three years; no other relationships or activities that could appear to have influenced the submitted work.

Ethical approval: The EPIC study was approved by the IARC ethical committee and by the local ethics committees relevant for each study centre. All participants gave informed consent.

Data sharing: No additional data available.

1 Rehm J, Mathers C, Popova S, Thavorncharoensap M, Teerawattananon $Y$, Patra J. Global burden of disease and injury and economic cost attributable to alcohol use and alcohol-use disorders. Lancet 2009;373:2223-33.

2 Baan R, Straif K, Grosse Y, Secretan B, El Ghissassi F, Bouvard V, et al. Carcinogenicity of alcoholic beverages. Lancet Oncol 2007;8:292-3.

3 Secretan B, Straif K, Baan R, Grosse Y, El Ghissassi F, Bouvard V, et al. A review of human carcinogens-part E: tobacco, areca nut, alcohol, coal smoke, and salted fish. Lancet Oncol 2009;10:1033-4.

4 Hashibe M, Brennan P, Chuang SC, Boccia S, Castellsague X, Chen C, et al. Interaction between tobacco and alcohol use and the risk of head and neck cancer: pooled analysis in the International Head and Neck Cancer Epidemiology Consortium. Cancer Epidemiol Biomarkers Prev 2009;18:541-50.

5 Allen NE, Beral V, Casabonne D, Kan SW, Reeves GK, Brown A, et al. Moderate alcohol intake and cancer incidence in women. J Natl Cancer Inst 2009;101:296-305.

6 World Cancer Research Fund/American Institute for Cancer Research Food, nutrition, physical activity, and the prevention of cancer: a global perspective. WCRF/AICR, 2007.

7 Riboli E, Hunt KJ, Slimani N, Ferrari P, Norat T, Fahey M, et al. European prospective investigation into cancer and nutrition (EPIC): study populations and data collection. Public Health Nutr 2002:5:1113-24.

8 Riboli E, Kaaks R. The EPIC project: rationale and study design. European Prospective Investigation into Cancer and Nutrition. Int J Epidemiol 1997:26(suppl 1):S6-14.

9 Kaaks R, Slimani N, Riboli E. Pilot phase studies on the accuracy of dietary intake measurements in the EPIC project: overall evaluation of results. European Prospective Investigation into Cancer and Nutrition. Int J Epidemiol 1997;26(suppl 1):S26-36.

10 Sieri S, Agudo A, Kesse E, Klipstein-Grobusch K, San-Jose B, Welch AA, et al. Alcohol consumption in EPIC cohorts from ten European countries. IARC Sci Publ 2002;156:173-6.

11 Slimani N, Ferrari P, Ocke M, Welch A, Boeing H, Liere M, et al. Standardization of the 24-hour diet recall calibration method used in the European Prospective Investigation into Cancer and Nutrition (EPIC): general concepts and preliminary results. Eur / Clin Nutr 2000;54:900-17.

12 Boffetta P, Couto E, Wichmann J, Ferrari P, Trichopoulos D, Bueno-de-Mesquita HB, et al. Fruit and vegetable intake and overall cancer risk in the European Prospective Investigation Into Cancer and Nutrition (EPIC). J Natl Cancer Inst 2010;102:529-37.

13 Ferlay J, Shin HR, Bray F, Forman D, Mathers C, Parkin DM. GLOBOCAN 2008: cancer incidence and mortality worldwide. 2008. www-dep. iarc.fr/.

14 Symons MI, Moore DT. Hazard rate ratio and prospective epidemiological studies. J Clin Epidemiol 2002;55:893-9.

15 Weikert C, Dietrich T, Boeing H, Bergmann M, Boutron-Ruault MC Clavel-Chapelon F, et al. Lifetime and baseline alcohol intake and risk of cancer of the upper aero-digestive tract in the European Investigation into Cancer and Nutrition (EPIC) study. Int I Cancer 2009;125:406-12.

16 Tjonneland A, Christensen J, Olsen A, Stripp C, Thomsen BL, Overvad K, et al. Alcohol intake and breast cancer risk: the European
Prospective Investigation into Cancer and Nutrition (EPIC). Cancer Causes Control 2007;18:361-73.

17 Rohrmann S, Linseisen J, Vrieling A, Boffetta P, Stolzenberg-Solomon RZ, Lowenfels AB, et al. Ethanol intake and the risk of pancreatic cancer in the European Prospective Investigation into Cancer and Nutrition (EPIC). Cancer Causes Control 2009;20:785-94.

18 Rohrmann S, Linseisen J, Key TJ, Jensen MK, Overvad K, Johnsen NF, et al. Alcohol consumption and the risk for prostate cancer in the European Prospective Investigation into Cancer and Nutrition. Cancer Epidemiol Biomarkers Prev 2008;17:1282-7.

19 Rohrmann S, Linseisen J, Boshuizen HC, Whittaker J, Agudo A, Vineis $P$, et al. Ethanol intake and risk of lung cancer in the European Prospective Investigation into Cancer and Nutrition (EPIC). Am J Epidemiol 2006;164:1103-14.

20 Ferrari P, Jenab M, Norat T, Moskal A, Slimani N, Olsen A, et al. Lifetime and baseline alcohol intake and risk of colon and rectal cancers in the European Prospective Investigation into Cancer and Nutrition (EPIC). Int / Cancer 2007:121:2065-72.

21 Wareham NJ, Jakes RW, Rennie KL, Schuit J, Mitchell J, Hennings S, et al. Validity and repeatability of a simple index derived from the short physical activity questionnaire used in the European Prospective Investigation into Cancer and Nutrition (EPIC) study. Public Health Nutr 2003;6:407-13.

22 Hardy RI, Thompson SG. Detecting and describing heterogeneity in meta-analysis. Stat Med 1998;17:841-56.

23 Higgins JP, Thompson SG, Deeks JJ, Altman DG. Measuring inconsistency in meta-analyses. BMJ 2003;327:557-60.

24 Bagnardi V, Blangiardo M, La Vecchia C, Corrao G. A meta-analysis of alcohol drinking and cancer risk. Br J Cancer 2001;85:1700-5.

25 Arico S, Corrao G, Torchio P, Galatola G, Tabone M, Valenti M, et al. A strong negative association between alcohol consumption and the risk of hepatocellular carcinoma in cirrhotic patients. A case-contro study. Eur J Epidemiol 1994;10:251-7.

26 Rehm J, Klotsche J, Patra J. Comparative quantification of alcohol exposure as risk factor for global burden of disease. Int J Methods Psychiatr Res 2007;16:66-76.

27 World Health Organization. Global status report. Country profiles. WHO, 2011. www.who.int/substance_abuse/publications/ global_alcohol_report/en/index.html.

28 World Health Organization. Global information system on alcohol and health (GISAH). 2007. http://apps.who.int/globalatlas/default. asp.

29 Rehm I, Kehoe T, Gmel G, Stinson F, Grant B. Statistical modeling of volume of alcohol exposure for epidemiological studies of population health: the US example. Popul Health Metr 2010;8:3.

30 Kehoe T, Gmel G, Rehm J. Fitting different distributions to alcohol consumption among drinkers. CAMH, 2009.

31 Kokkevi A, Loukadakis M, Plagianakou S, Politikou K, Stefanis C. Sharp increase in illicit drug use in Greece: trends from a general population survey on licit and illicit drug use. Eur Addict Res 2000;6:42-9.

32 Flegal KM, Williamson DF, Graubard BI. Fraction of premature death in the Canadian population that were attributable to overweight and obesity. Can J Public Health 2004;95:235.

33 Flegal KM, Williamson DF, Graubard BI. Using adjusted relative risks to calculate attributable fractions. Am I Public Health 2006;96:398-9.

34 Greenland S, Robins JM. Conceptual problems in the definition and interpretation of attributable fractions. Am J Epidemiol 1988;128:1185-97.

35 Rockhill B, Newman B, Weinberg C. Use and misuse of population attributable fractions. Am I Public Health 1998:88:15-9.

36 Ferlay J, Bray F, Pisani P, Parkin DM. GLOBOCAN 2002: cancer incidence, mortality and prevalence worldwide. 2004. www-dep.iarc. $\mathrm{fr} /$.

37 Rehm J, Sulkowska U, Manczuk M, Boffetta P, Powles J, Popova S, et al. Alcohol accounts for a high proportion of premature mortality in central and eastern Europe. Int J Epidemiol 2007;36:458-67.

38 Boffetta P, Hashibe M, La Vecchia C, Zatonski W, Rehm J. The burden of cancer attributable to alcohol drinking. Int / Cancer 2006;119:884-7.

39 Boffetta P, Tubiana M, Hill C, Boniol M, Aurengo A, Masse R, et al. The causes of cancer in France. Ann Oncol 2009;20:550-5.

40 Corrao G, Rubbiati L, Zambon A, Arico S. Alcohol-attributable and alcohol-preventable mortality in Italy. A balance in 1983 and 1996. Eur J Public Health 2002;12:214-23.

41 Danaei G, Vander Hoorn S, Lopez AD, Murray CJ, Ezzati M. Causes of cancer in the world: comparative risk assessment of nine behavioural and environmental risk factors. Lancet 2005;366:1784-93.

42 Grant I, Springbett A, Graham L. Alcohol attributable mortality and morbidity: alcohol population attributable fractions for Scotland. Scotland NHS, 2009. www.isdscotland.org/isd/5964.html. 
43 Jones L, Bellis MA, Dedman D, Sumnall H, Tocque K. Alcoholattributable fractions for England-alcohol-attributable mortality and hospital admissions. Centre for Public Health, 2008.

44 WHO IARC. Attributable causes of cancer in France in the year 2000. IARC Working Group Reports, Vol 3, 2007.

45 World Cancer Research Fund/American Institute for Cancer Research Policy and action for cancer prevention. Food, nutrition, and physical activity: a global perspective. WCRF/AICR, 2007.

46 Corrao G, Bagnardi V, Zambon A, La Vecchia C. A meta-analysis of alcohol consumption and the risk of 15 diseases. Prev Med 2004;38:613-9.

47 Di Castelnuovo A, Costanzo S, Bagnardi V, Donati MB, lacoviello L, de Gaetano G. Alcohol dosing and total mortality in men and women: an updated meta-analysis of 34 prospective studies. Arch Intern Med 2006;166:2437-45.

48 Mukamal KJ, Chen CM, Rao SR, Breslow RA. Alcohol consumption and cardiovascular mortality among US adults, 1987 to 2002. J Am Coll Cardiol 2010;55:1328-35.

49 Klatsky AL. Alcohol and cardiovascular health. Physiol Behav 2010;100:76-81

50 Di Castelnuovo A, Costanzo S, Donati MB, lacoviello L, de Gaetano G. Prevention of cardiovascular risk by moderate alcohol consumption: epidemiologic evidence and plausible mechanisms. Intern Emerg Med 2010;5:291-7.
51 Corrao G, Bagnardi V, Zambon A, Arico S. Exploring the doseresponse relationship between alcohol consumption and the risk of several alcohol-related conditions: a meta-analysis. Addiction 1999;94:1551-73.

52 Taylor B, Rehm J. When risk factors combine: the interaction between alcohol and smoking for aerodigestive cancer, coronary heart disease, and traffic and fire injury. Addict Behav 2006;31:1522-35.

53 Hashibe M, Brennan P, Benhamou S, Castellsague X, Chen C, Curado MP, et al. Alcohol drinking in never users of tobacco, cigarette smoking in never drinkers, and the risk of head and neck cancer: pooled analysis in the International Head and Neck Cancer Epidemiology Consortium. J Natl Cancer Inst 2007;99:777-89.

54 Bagnardi V, Blangiardo M, La Vecchia C, Corrao G. Alcohol consumption and the risk of cancer: a meta-analysis. Alcohol Res Health 2001;25:263-70.

55 Boeing H, Korfmann A, Bergmann MM. Recruitment procedures of EPIC-Germany. European Investigation into Cancer and Nutrition. Ann Nutr Metab 1999;43:205-15.

56 World Health Organization. European alcohol action plan. WHO, 1993.

Accepted: 04 January 2011 